\title{
Metastatic pancreatic cancer: Is gemcitabine still the best standard treatment? (Review)
}

\author{
MARIACRISTINA DI MARCO, ROBERTO DI CICILIA, MARINA MACCHINI, ELISABETTA NOBILI, \\ SILVIA VECCHIARELLI, GIOVANNI BRANDI and GUIDO BIASCO \\ 'L. e A. Seràgnoli' Department of Hematology and Oncological Sciences, \\ S. Orsola-Malpighi Hospital, University of Bologna, Via Massarenti 9, I-40138 Bologna, Italy
}

Received September 14, 2009; Accepted November 2, 2009

DOI: $10.3892 /$ or_00000749

\begin{abstract}
Pancreatic ductal adenocarcinoma is the fourth cause of death in the Western world. Surgery remains the only treatment offering an advantage in terms of overall survival (5-year survival range, 15-25\%), but unfortunately only $10-20 \%$ of patients present resectable disease at the time of diagnosis. Hence chemotherapy, possibly combined with radiation therapy, remains the only treatment option aimed at palliation of symptoms and ensuring a better quality of life. Notwithstanding the efforts to find more effective therapies for the treatment of pancreatic cancer, significant results have not yet been achieved. Increasing interest has focused on integrated treatments, i.e. chemotherapy combined with targeted therapies, and a better selection of patients. This study examines the principal clinical trials that will help give clinicians an overview of the progress made in the systemic therapy for advanced pancreatic cancer patients in recent years.
\end{abstract}

\section{Contents}

1. Introduction

2. From 5-fluorouracil to gemcitabine

3. Gemcitabine-combined regimens

4. Multidrug combination regimens

5. Targeted therapies

6. Vascular endothelial growth factor (VEGF)

7. Other molecules

8. Second-line treatments

9. Conclusions

Correspondence to: Dr Mariacristina Di Marco, 'L. e A. Seràgnoli' Department of Hematology and Oncological Sciences, S. OrsolaMalpighi Hospital, University of Bologna, Via Massarenti 9, I-40138 Bologna, Italy

E-mail: mariacristina.dimarco@unibo.it

Key words: advanced pancreatic cancer, gemcitabine, capecitabine, platinum compounds, targeted therapies

\section{Introduction}

Pancreatic ductal adenocarcinoma is one of the commonest gastrointestinal tract malignancies and the fourth cause of cancer-related death in the Western world.

The natural history of this tumour is characterized by a poor outcome for all stages of disease and only 1-4\% of pancreatic cancer patients are still alive at 5 years from diagnosis (1).

Despite the advances in cancer therapy, the treatment of pancreatic cancer patients remains one of the major challenges of medical oncology. To date, the radical surgical resection of pancreatic ductal adenocarcinoma remains the only treatment offering an advantage in terms of overall survival (5-year survival range, 15-25\%). Unfortunately, in most cases, the disease is no longer susceptible to a radical surgery when it is clinically manifested. Hence, only $10-20 \%$ of patients present resectable disease at the time of diagnosis (2).

For the majority of patients with pancreatic cancer, chemotherapy, possibly combined with radiotherapy, remains the only treatment option aimed at palliating symptoms and ensuring a better quality of life, without changing the poor prognosis.

Notwithstanding the efforts to find more effective therapies for the treatment of pancreatic cancer, significant results have not yet been achieved. Increasing interest has focused on integrated treatments, i.e. chemotherapy combined with targeted therapy.

The objective of this review is to help clinicians focus on what has been done in systemic palliative therapy for the advanced pancreatic patients in recent years. We examined the principal clinical trials which used cytotoxic chemotherapeutic agents or molecular-targeted therapies or both.

\section{From 5-fluorouracil to gemcitabine}

5-Fluorouracil (5-FU) was considered the only chemotherapeutic option for about 20 years until the registration of gemcitabine. Several trials showed that chemotherapy leads to an improved survival and quality of life compared to the best supportive care (BSC) in advanced pancreatic cancer patients $(3,4)$, but the combination of 5 -FU with other drugs did not prove superior to the antimetabolite alone (5-9) (Table I). 
Table I. 5-Fluorouracil based chemotherapy regimens.

\begin{tabular}{|c|c|c|c|c|c|c|c|c|}
\hline Regimen & Refs. & $\begin{array}{c}\text { Type of } \\
\text { study }\end{array}$ & $\begin{array}{c}\text { No. of } \\
\text { patients }\end{array}$ & $\begin{array}{l}\text { Stage } \\
\text { disease }\end{array}$ & $\begin{array}{l}\text { Median } \\
\text { survival }\end{array}$ & PFS & 1-year survival (\%) & $\mathrm{RR}(\%)$ \\
\hline FU vs. FU + CDDP & Ducreux et al (7) & III & 207 & $\mathrm{LA} / \mathrm{M}$ & $\begin{array}{l}102 \text { vs. } 112 \text { days } \\
\quad(\mathrm{p}=0.10)\end{array}$ & 59 vs. 73 days & $\begin{array}{l}8.7 \text { vs. } 17.3 \\
(\mathrm{p}=0.07)\end{array}$ & $\begin{array}{l}0 \text { vs. } 12 \\
(p=0.01)\end{array}$ \\
\hline $\begin{array}{l}\text { FU (PVI) vs. } \\
\text { FU (PVI) + mitomycin }\end{array}$ & Maisey et al (8) & III & 209 & $\mathrm{LA} / \mathrm{M}$ & $\begin{array}{l}5.1 \text { vs. } 6.5 \mathrm{mo} \\
\quad(p=0.338)\end{array}$ & $\begin{array}{l}2.8 \text { vs. } 3.8 \mathrm{mo} \\
\quad(\mathrm{p}=0.14)\end{array}$ & $\begin{array}{l}23.5 \text { vs. } 32.2 \\
(\mathrm{p}=0.338)\end{array}$ & $\begin{array}{c}8.4 \text { vs. } 17.6 \\
(p=0.04)\end{array}$ \\
\hline FU vs. OXA vs. OXFU & Ducreux et al (9) & II & 65 & $\mathrm{LA} / \mathrm{M}$ & $\begin{array}{l}\text { 5-FU: } 2.4 \mathrm{mo} \\
\text { OXA: } 3.4 \mathrm{mo} \\
\text { OXFU: } 9.0 \mathrm{mo}\end{array}$ & $\begin{array}{l}\text { 5-FU: } 1.5 \mathrm{mo} \\
\text { OXA: } 2.0 \mathrm{mo} \\
\text { OXFU: } 4.2 \mathrm{mo}\end{array}$ & - & OXFU: 10 \\
\hline
\end{tabular}

FU, 5-fluorouracil; CDDP, cisplatin; OXA, oxaliplatin; OXFU, OXA + FU; PVI, protracted venous infusion; LA, locally advanced; M, metastatic; OS, overall survival; PFS, progression-free survival; RR, response rate.

During the 1990s, several trials were designed to find new active drugs in pancreatic cancer treatment and the nucleoside analogous gemcitabine (2'-deoxy-2',2'-difluorocytinide) has aroused considerable interest (10-12). The pivotal trial found a clear improvement of the one-year median survival rate in patients treated with gemcitabine over those who received 5 -FU ( 18 vs. $2 \%, \mathrm{p}=0.0001$ ). That study also introduced the concept of clinical benefit response (CBR) that was defined as a $\geq 50 \%$ reduction in pain intensity, daily analgesic consumption or $\geq 20$ point improvement in Karnofsky performance status (PS) for $\geq 4$ consecutive weeks. CBR was significantly improved in gemcitabine treated patients $(\mathrm{p}=0.0022)(13)$.

Several recent clinical trials proposed different gemcitabine administration schedules. Phase I and II studies showed the effectiveness of the fixed-dose rate regimen (FDR) (14). Based on the fact that anti-cancer drug activity was improved by a prolonged infusion, a randomized phase II trial compared the regimen of $2200 \mathrm{mg} / \mathrm{m}^{2}$ with a standard 30-min infusion with a FDR regimen of $1500 \mathrm{mg} / \mathrm{m}^{2}$ over $150 \mathrm{~min}$ in locally advanced or metastatic pancreatic cancer patients $(91 \%)$. The FDR regimen resulted in a better OS than the standard regimen $(\mathrm{p}=0.013)$, but more severe adverse events, namely hematological toxicity, were observed (15). However, a confirmatory phase III trial failed to demonstrate an improvement in OS of gemcitabine FDR regimen over the standard administration (16). In conclusion, the optimal clinical application of gemcitabine FDR remains a matter of lively debate.

\section{Gemcitabine-combined regimens}

Many phase II studies demonstrated the efficacy of gemcitabine combination treatments, but none of the randomized phase III trials confirmed the improvement in OS of gemcitabine-based doublets compared to gemcitabine alone $(14,17)$. However, an advantage in six-month mortality was given by combining gemcitabine-fluoropyrimidine analogues and gemcitabine-platinum analogues, as demonstrated in the meta-analysis of Heinemann and colleagues
$(3,18)$. Another phase II study confirmed the improved efficacy of the gemcitabine-based combination with better results for patients with a good baseline PS (19). Table II summarizes the randomized phase III trials comparing gemcitabine combination regimens over gemcitabine alone.

Gemcitabine and 5-fluorouracil. Based on the complementary pharmacology of their mechanisms of action, the combination of 5-FU and gemcitabine was evaluated in many phase I and II trials. The interpretation of results suggested a clinical activity of the association schedule with a good tolerability (19-22).

The first important randomized phase III trial evaluated the combination regimen compared to gemcitabine alone. The objective response (OR) and median OS did not differ between the two treatment arms (23). In addition, the Italian Group for Clinical Oncology Research (GOIRC) evaluated the efficacy of gemcitabine in combination with or without continuous 5-FU infusion. This trial also failed to report a significant improvement of median OS (31 vs. 30 weeks) and median progression-free survival (PFS) (14 vs. 18 weeks), in the experimental arm (24).

Gemcitabine and capecitabine. Capecitabine is an orally administered fluorouracil pro-drug, which is activated by a three-step targeted process (carboxylesterases, cytidine deaminase and thymidine phosphorylase respectively). This drug mimics the continuous infusion of 5-FU and its intratumoral activation improved the therapeutic index and reduced toxicity in normal tissue.

Phase I and II trials showed discordant results regarding the efficacy of the gemcitabine-capecitabine combination. These studies used different schedules but none of them were able to demonstrate a certain advantage over gemcitabine alone (25-29).

An abstract of one important phase III trial involving 533 patients reported an improvement in OS $(\mathrm{p}=0.014)$ and one-year survival in patients who received gemcitabine $\left(1000 \mathrm{mg} / \mathrm{m}^{2}\right)$ on days $1,8,15$ plus capecitabine $(1660 \mathrm{mg} /$ $\mathrm{m}^{2} /$ day) on days 1-21 every 28 , compared to those who 
Table II. Gemcitabine based chemotherapy regimens.

\begin{tabular}{|c|c|c|c|c|c|c|c|c|}
\hline Regimen & Refs. & $\begin{array}{l}\text { Type of } \\
\text { study }\end{array}$ & $\begin{array}{l}\text { No. of } \\
\text { patients }\end{array}$ & $\begin{array}{c}\text { Stage } \\
\text { disease }\end{array}$ & $\begin{array}{c}\text { Median } \\
\text { survival (mo) }\end{array}$ & PFS & $\begin{array}{c}\text { 1-year } \\
\text { survival (\%) }\end{array}$ & $\mathrm{RR}(\%)$ \\
\hline GEMFU vs. GEM & Berlin et al (19) & III & 327 & $\mathrm{LA} / \mathrm{M}$ & $\begin{array}{c}6.7 \text { vs. } 5.4 \mathrm{mo} \\
\quad(p=0.09)\end{array}$ & $\begin{array}{c}3.4 \text { vs. } 2.2 \mathrm{mo} \\
\quad(\mathrm{p}=0.022)\end{array}$ & - & 6.9 vs. 5.6 \\
\hline GEMCAPE vs. GEM & Cunningham et al (30) & III & 533 & $\mathrm{LA} / \mathrm{M}$ & 7.4 vs. $6 \mathrm{mo}$ & - & 26 vs. 19 & $\begin{array}{c}17 \text { vs. } 4 \\
(p=0.008)\end{array}$ \\
\hline GEMCAPE vs. GEM & Herrmann et al (31) & III & 319 & $\mathrm{LA} / \mathrm{M}$ & $\begin{array}{c}8.4 \text { vs. } 7.2 \mathrm{mo} \\
\quad(p=0.234)\end{array}$ & $\begin{array}{c}4.3 \text { vs. } 3.9 \mathrm{mo} \\
\quad(\mathrm{p}=0.103)\end{array}$ & 32 vs. 30 & 10 vs. 7.8 \\
\hline GEMCIS vs. GEM & Colucci et al (47) & III & 107 & $\mathrm{LA} / \mathrm{M}$ & $\begin{array}{c}7.5 \text { vs. } 5 \mathrm{mo} \\
(\mathrm{p}=0.43)\end{array}$ & $\begin{array}{c}4.6 \text { vs. } 1.8 \mathrm{mo} \\
\quad(\mathrm{p}=0.048)\end{array}$ & 11.3 vs. 11 & $\begin{array}{c}26.4 \text { vs. } 9.2 \\
(\mathrm{p}=0.02)\end{array}$ \\
\hline GEMCIS vs. GEM & Heinemann et al (48) & III & 195 & $\mathrm{LA} / \mathrm{M}$ & $\begin{array}{c}7.6 \text { vs. } 6 \text { mo } \\
\quad(p=0.15)\end{array}$ & $\begin{array}{c}5.3 \text { vs. } 3.1 \mathrm{mo} \\
\quad(\mathrm{p}=0.053)\end{array}$ & $\begin{array}{c}25.3 \text { vs. } 24.7 \\
(p=0.21)\end{array}$ & 10.2 vs. 8.2 \\
\hline GEMOX vs. GEM & Louvet et al (46) & III & 313 & $\mathrm{LA} / \mathrm{M}$ & $\begin{array}{c}9.0 \text { vs. } 7.1 \mathrm{mo} \\
\quad(p=0.13)\end{array}$ & $\begin{array}{c}5.8 \text { vs. } 3.7 \mathrm{mo} \\
\quad(p=0.04)\end{array}$ & $\begin{array}{c}34.7 \text { vs. } 27.8 \\
(p=0.22)\end{array}$ & $\begin{array}{c}26.8 \text { vs. } 17.3 \\
\quad(p=0.04)\end{array}$ \\
\hline GEMIRI vs. GEM & Rocha-Lima et al (54) & III & 360 & $\mathrm{LA} / \mathrm{M}$ & $\begin{array}{c}6.3 \text { vs. } 6.6 \mathrm{mo} \\
\quad(p=0.789)\end{array}$ & $\begin{array}{c}3.5 \text { vs. } 3.0 \mathrm{mo} \\
(\mathrm{p}=0.352)\end{array}$ & 21 vs. 22 & $\begin{array}{c}16.1 \text { vs. } 4.4 \\
(\mathrm{p}<.001)\end{array}$ \\
\hline GEM-EXE vs. GEM & Abou-Alfa et al (55) & III & 349 & $\mathrm{LA} / \mathrm{M}$ & $\begin{array}{c}6.7 \text { vs. } 6.2 \mathrm{mo} \\
\quad(p=0.52)\end{array}$ & $\begin{array}{c}3.7 \text { vs. } 3.8 \mathrm{mo} \\
(\mathrm{p}=0.22)\end{array}$ & 23 vs. 21 & 6.3 vs. 4.6 \\
\hline GEM-PEM vs. GEM & Oettle et al (50) & III & 565 & $\mathrm{LA} / \mathrm{M}$ & $\begin{array}{c}6.2 \text { vs. } 6.3 \mathrm{mo} \\
(p=0.8477)\end{array}$ & $\begin{array}{c}3.9 \text { vs. } 3.3 \mathrm{mo} \\
\quad(p=0.11)\end{array}$ & 21.4 vs. 20.1 & $\begin{array}{c}14.8 \text { vs. } 7.1 \\
(p=0.004)\end{array}$ \\
\hline
\end{tabular}

FU, 5-fluorouracil; GEM, gemcitabine; CAPE, capecitabine; GEMFU, GEM + FU; GEMCAPE, GEM + CAPE; GEMCIS, GEM + CDDP; GEMOX, GEM + oxaliplatin; GEMIRI, GEM + irinotecan; GEM-EXE, GEM + exatecan; GEM-PERM, GEM + pemetrexed; LA, locally advanced; M, metastatic; OS, overall survival; PFS, progression-free survival; RR, response rate.

received gemcitabine alone, with a good profile of toxicity in both arms (30). A second phase III trial randomized 329 patients in gemcitabine $\left(1000 \mathrm{mg} / \mathrm{m}^{2}\right.$ on days 1,8$)$ plus capecitabine $\left(1300 \mathrm{mg} / \mathrm{m}^{2} /\right.$ day days $1-14$ every 21$)$ arm and in the standard gemcitabine regimen arm. OS was not statistically significant different between the two arms $(p=0.23)$. However, the patients with good baseline PS (score 90-100) who received the combination regimen had a significant improvement in survival ( $\mathrm{p}=0.014)(31)$. A more recent phase III trial analysed the CBR and quality of life (QOL) in patients who received gemcitabine and capecitabine compared to gemcitabine alone, but did not disclose differences between the two treatment arms (32).

Gemcitabine and tegafur/UFT or $S$-1. Both drugs are oral fluoropyrimidines that mimic the effect of a continuous infusion of 5-FU.

UFT, a combination of 1-5-FU (tegafur) and uracil, was evaluated in addition to gemcitabine in some phase II trials with encouraging results in terms of median OS (11 months) and a median TTP (6 months) $(33,34)$.

In 2004 Lee and colleagues obtained a median OS of 5.8 months and a median TTP of 4.2 months from the same regimen. These modest results can be explained by the particular kind of population examined in the trial, represented only by patients with metastatic disease (35).

Ueno and colleagues reported a good anticancer activity of the combination of S-1 with gemcitabine in 18 chemotherapy-naïve patients in a phase I trial (36). A median OS of 10.1 months and a median PFS of 5.9 months were subsequently shown by a phase II study (Ueno $\mathrm{H}$, et al, Gastrointestinal Cancers Symposium: 148, 2007). Similar data were obtained by a more recent study (Oh $\mathrm{H}$, et al, Gastrointestinal Cancers Symposium: 212, 2008). Both the last two studies are reported in abstract form only. Nevertheless, there are no confirmatory randomized studies demonstrating the superiority of new regimens compared to gemcitabine monotherapy.

Gemcitabine and platinum compounds. Platinum derivatives are frequently used in combination schedules to treat pancreatic cancer.

Encouraging results were obtained in some phase II trials using different schedules with an overall TTP from 3.6 to 5.7 and an OS from 5.6 to 9.5 months $(37-44,47)$. In particular, a preliminary trial assessed the combination of gemcitabine $\left(1000 \mathrm{mg} / \mathrm{m}^{2}\right.$ as a $10 \mathrm{mg} / \mathrm{m}^{2} / \mathrm{min}$ infusion on day 1) plus oxaliplatin $\left(100 \mathrm{mg} / \mathrm{m}^{2}\right.$ as a 2 -h infusion on day 2 every two 
Table III. Gemcitabine and cisplatin based chemotherapy regimens.

\begin{tabular}{|c|c|c|c|c|c|c|c|c|}
\hline Regimen & Refs. & $\begin{array}{l}\text { Type of } \\
\text { study }\end{array}$ & $\begin{array}{c}\text { No. of } \\
\text { patients }\end{array}$ & $\begin{array}{l}\text { Stage } \\
\text { disease }\end{array}$ & $\begin{array}{c}\text { Median } \\
\text { survival (mo) }\end{array}$ & $\begin{array}{l}\text { PFS } \\
(\mathrm{mo})\end{array}$ & $\begin{array}{c}\text { 1-year } \\
\text { survival (\%) }\end{array}$ & $\mathrm{RR}(\%)$ \\
\hline GEMCIS & Heinemann et al (37) & II & 41 & $\mathrm{LA} / \mathrm{M}$ & 8.2 & 4.3 & 27 & 11 \\
\hline GEMCIS & Philip et al (39) & II & 42 & $\mathrm{LA} / \mathrm{M}$ & 7.1 & 5.4 & 19 & 26 \\
\hline GEMCIS & Cascinu et al (38) & II & 45 & $\mathrm{LA} / \mathrm{M}$ & 5.6 & 3.6 & - & 9 \\
\hline GEM vs. GEMCIS & Colucci et al (47) & III & 107 & $\mathrm{LA} / \mathrm{M}$ & $\begin{array}{l}5 \text { vs. } 7.5 \\
(p=0.43)\end{array}$ & $\begin{array}{l}1.8 \text { vs. } 4.6 \\
(p=0.048)\end{array}$ & 11 vs. 11.3 & $\begin{array}{c}9.2 \text { vs. } 26.4 \\
(p=0.02)\end{array}$ \\
\hline GEMCIS vs. GEM & Heinemann et al (48) & III & 195 & $\mathrm{LA} / \mathrm{M}$ & $\begin{array}{c}7.6 \text { vs. } 6.0 \\
(p=0.15)\end{array}$ & $\begin{array}{l}5.3 \text { vs. } 3.1 \\
(p=0.053)\end{array}$ & $\begin{array}{c}25.3 \text { vs. } 24.7 \\
\quad(p=0.21)\end{array}$ & 10.2 vs. 8.2 \\
\hline GEMCIS & Clayton et al (44) & II & 36 & $\mathrm{LA} / \mathrm{M}$ & 9.5 & 5.7 & 41.7 & - \\
\hline GEMCIS & Ko et al (40) & II & 51 & M & 7.1 & 3.9 & 29 & 19.1 \\
\hline GEMCIS & Ueno et al (42) & II & 38 & M & 7.5 & 4.2 & 24 & 26 \\
\hline
\end{tabular}

GEMCIS, gemcitabine + cisplatin; GEM, gemcitabine; LA, locally advanced; M, metastatic; PFS, progression-free survival; RR, response.

weeks) (GEMOX regimen) in 64 eligible previously untreated advanced pancreatic cancer patients. A median OS of 8.7 months and 11.5 months were reported in metastatic and locally advanced patients, respectively (45).

The only multicenter phase III study involving 313 advanced patients compared the GEMOX regimen to gemcitabine alone. The combination regimen offered a significant improvement of PFS (5.58 vs. 3.7 months), CBR (38.2 vs. $26.9 \%)$ and response rate (RR) (26.8 vs. $17.3 \%)$ but no advantage was seen in terms of OS (46) (Table II). Moreover, neurotoxicity and higher grade thrombocytopenia were observed in the experimental arm. Colucci and colleagues confirmed the advantage of the platinum doublet in terms of CBR and median TTP, but median OS did not reach a statistical significance (47). Heinemann and colleagues in phase III trial demonstrated an improvement in median OS for the addition of cisplatin to gemcitabine, although these data did not yield statistical evidence (48), as summarized in Table III.

Gemcitabine and pemetrexed. Pemetrexed is a multitargeted antifolate that has a synergistic activity with gemcitabine. Miller and colleagues in phase II trial tested the activity of pemetrexed as a single agent in advanced pancreatic cancer patients. They reported an OS of 6.5 months and a median time to treatment failure of 4 months (49). A phase III trial on 565 advanced pancreatic patients randomly assigned either gemcitabine plus pemetrexed or gemcitabine alone. No significant differences between the two treatment arms were observed in terms of OS and PFS (50).

Gemcitabine and topoisomerase inhibitors. Irinotecan (CPT-11) and Exatecan are the most widely used topoisomerase inhibitors in pancreatic cancer treatment. Their antitumor activity was investigated in some phase II trials, but without great emphasis $(51,52)$. The first phase II trial to evaluate the combination regimen with gemcitabine showed a median survival of 5.7 months and a median TTP of 2.8 months, and the phase III randomized study confirmed these data $(53,54)$. However, other trials failed to confirm the lack of improvement in OS by the addition of the topoisomerase inhibitors to gemcitabine, and in some cases the combination led to major toxicity $(55,56)$.

Gemcitabine and taxanes. Antitumoral action of taxanes is due to their mechanism of microtubule stabilization and consequently to the cell cycle arrest. The association of gemcitabine with paclitaxel or docetaxel in advanced pancreatic patients was studied in many phase I and II trials, but none of them showed additional clinical benefit (57-59). The major treatment-related toxicity, namely myelosuppression, precluded the development of randomized trials. Overall, these studies showed a median survival from 4.7 to 8.9 months and a RR from 12.5 to $18 \%$, but severe neutropenia occurred in about $50 \%$ of patients in both trials $(60,61)$.

Recently Genexol-PM, a novel miceller paclitaxel, was tested in a phase II trial in comparison to gemcitabine alone. The micellar formulation of paclitaxel had a similar efficacy to gemcitabine with a PFS and OS of 3.0 and 6.2 months respectively (Saif MW, et al, Gastrointestinal Cancer Symposium, abs. 269, 2008). Further trials on the genexol-PM and gemcitabine combination are planned.

\section{Multidrug combination regimens}

The first phase III trial to analyze the efficacy of a multi-drug combination was carried out by Reni and colleagues in 2005 comparing the activity of cisplatin, epirubicin, gemcitabine and 5-FU (PEFG) to gemcitabine alone. The PFS was about $60 \%$ in the combination arm compared to $28 \%$ in the standard arm treatment $(\mathrm{p}=0.003)$, the RR was about 38 vs. $8.5 \%$, 
Table IV. Phase III trials involving targeted therapies.

\begin{tabular}{|c|c|c|c|c|c|c|c|c|c|}
\hline Regimen & Refs. & $\begin{array}{l}\text { Type of } \\
\text { study }\end{array}$ & $\begin{array}{l}\text { No. of } \\
\text { patients }\end{array}$ & $\begin{array}{l}\text { Stage } \\
\text { disease }\end{array}$ & $\begin{array}{c}\text { Median } \\
\text { survival (mo) }\end{array}$ & $\begin{array}{l}\text { PFS } \\
(\mathrm{mo})\end{array}$ & $\begin{array}{c}1 \text {-year } \\
\text { survival }(\%)\end{array}$ & $\mathrm{RR}(\%)$ & $\mathrm{SD}(\%)$ \\
\hline GEM + E vs. GEM + P & Moore et al (70) & III & 569 & M/LA & $\begin{array}{l}6.24 \text { vs. } 5.91 \\
\quad(p=0.038)\end{array}$ & $\begin{array}{l}3.75 \text { vs. } 3.55 \\
\quad(p=0.004)\end{array}$ & $\begin{array}{l}23 \text { vs. } 17 \\
(\mathrm{p}=0.023)\end{array}$ & 8.6 vs. 8 & 48.9 vs. 41.2 \\
\hline $\begin{array}{l}\text { GEM + Cetuximab } \\
\text { vs. GEM }\end{array}$ & Philip et al (76) & III & 766 & M/LA & $\begin{array}{l}6.5 . \text { vs. } 6 \\
(p=0.14)\end{array}$ & $\begin{array}{l}3.5 \text { vs. } 3 \\
(p=0.058)\end{array}$ & & 12 vs. 14 & \\
\hline $\begin{array}{l}\text { GEM + Bevacizumab } \\
\text { vs. GEM + P }\end{array}$ & Kindler $^{\mathrm{a}}$ & III & 602 & M/LA & $\begin{array}{l}5.7 \text { vs. } 6.0 \\
(\mathrm{p}=0.40)\end{array}$ & $\begin{array}{l}4.8 \text { vs. } 4.3 \\
(p=0.99)\end{array}$ & & 13.1 vs. 11.3 & 40.7 vs. 35.7 \\
\hline $\begin{array}{l}\text { GEM + E + } \\
\text { Bevacizumab } \\
\text { vs. GEM + E + P }\end{array}$ & Van Custem et al, (87) & III & 607 & M & 7.1 vs. 6 & $\begin{array}{l}4.6 \text { vs. } 3.6 \\
(p=0.0002)\end{array}$ & & 13.5 vs. 8.6 & 49.2 vs. 45.2 \\
\hline $\begin{array}{l}\text { Marimastat } \\
\text { (50 mg daily) vs. GEM }\end{array}$ & Bramhall et al (92) & III & 414 & $\mathrm{U}$ & 4.1 vs. 5.5 & 1.9 vs. 3.8 & 20 vs. 19 & 2.8 vs. 25.8 & \\
\hline $\begin{array}{l}\text { Marimastat + GEM } \\
\text { vs. GEM }\end{array}$ & Bramhall et al (91) & III & 239 & $\mathrm{U}$ & 5.4 vs. 5.4 & 3 vs. 3.1 & 18 vs. 17 & 11 vs. 16 & 50 vs. 56 \\
\hline $\begin{array}{l}\text { Tipifarnib + GEM } \\
\text { vs. GEM }\end{array}$ & Van Custem et al (95) & III & 688 & M/LA & $\begin{array}{l}6.3 \text { vs. } 6 \\
(p=0.75)\end{array}$ & $\begin{array}{c}3.7 \text { vs. } 3.6 \\
(\mathrm{p}=0.72)\end{array}$ & 27 vs. 24 & 6 vs. 8 & 53 vs. 52 \\
\hline
\end{tabular}

GEM, gemcitabine; P, placebo; E, erlotinib; PFS, progression free survival; OR, objective response; SD, stable disease; M, metastatic; LA, locally advanced; U, unresectable. ${ }^{a}$ Kindler et al, ASCO Gastrointestinal Cancers Symposium, abs. 108, 2007.

respectively, and the one-year survival rate was 38 vs. $21 \%$, respectively $(\mathrm{p}=0.11)(62)$. These good results led to tests on five-drug combinations such as CPT-11, gemcitabine, 5FU, leucovorin and cisplatin (G-FLIP): OS was 8.1 months and median TTP was about 6.1 months (56). Another interesting trial assessed the efficacy of an oxaliplatin, 5-FU and folinic acid (FOLFOX-6) combination in metastatic disease. The results, OS of 7.5 months and TTP of 4 months, are encouraging and justify further study (63). A combination of 5-FU, folinic acid and CPT-11 (FOLFIRI.3) with promising activity was also evaluated in the first-line setting yielding median OS and PFS of 12.1 and 5.6 months, respectively (64).

\section{Targeted therapies}

Epidermal growth factor receptor (EGFR) and HER2/neu in pancreatic cancer. EGFR, also known as HER-1 (human epidermal growth factor receptor) or ErbB-1, is a 170-kDA transmembrane glycoprotein that consists of a cysteine-rich extracellular ligand binding domain, a hydrophobic transmembrane domain and a cytoplasmatic tyrosine kinase domain.

EGFR is activated by several ligands including EGF (epidermal growth factor), TGF- $\alpha$ (trasforming growth factor $\alpha$ ), HB-EGF (heparin-binding EGF), amphiregulin, epiregulin, betacellulin and neuregulin. Activated EGFR forms homo- or heterodimeric complexes with another member of the ErbB receptor family which in turn leads to phosphorylation of the intracellular c-terminus kinase domain and activation of downstream signalling pathways.
HER2/neu is another member of the ErbB family of transmembrane tyrosine kinase receptors which is the preferred heterodimeric partner because no EGF family ligand is able to activate it.

The main signalling pathways activated by EGFR with or without HER2/neu are Ras/MAP kinase, phosphatidylinositol 3'-kinase (PI3K)/Akt, Janus kinase (JAK)/Stat and phospholipase C/protein kinase C. Ultimately all these pathways lead to activation of genes involved in cell proliferation, migration, adhesion, differentiation and apoptosis.

Dysregulation of EGFR and HER2/neu pathways can be found in a wide array of solid neoplasms including pancreatic cancer. EGFR and some of its ligands, EGF and TGF- $\alpha$, were frequently overexpressed (43, 46 and 54\%, respectively) in human pancreatic carcinoma and their coexpression seems to be correlated with an increased tumor aggressiveness and poor prognosis (65).

Studies evaluating the overexpression of HER-2 in pancreatic cancer by immunohistochemical labelling have yielded widely varying results with values ranging from 0 to $82 \%$, and only a few of these studies correlated this discrepancy to different methodologies $(66,67)$.

Since the dysregulation of EGFR and HER2/neu pathways is involved in the proliferation, invasion and spread of cancer cells, it is a logical assumption that targeting these receptors might exert an antitumoral effect. To date, two strategies to inhibit the ErbB receptor family have been investigated clinically: inhibitors of the tyrosine kinase domain and monoclonal antibodies directed against the extracellular ligand binding domain. Table IV summarizes phase III trials involving targeted therapies in combination with gemcitabine. 
Erlotinib. Erlotinib is an orally administered small tyrosine kinase inhibitor (TKI) molecule that competes with ATP (adenosine triphosphate) in binding the kinase domain and preventing downstream signal transduction.

Preliminary studies of erlotinib alone and in combination with gemcitabine showed an interesting antitumor activity, good tolerability with acne-like rash among the most common side-effects $(68,69)$.

The National Cancer Institute of Canada Clinical Trials Group (NCIC CTG) in cooperation with Australasian Gastrointestinal Tumor Group (AGITG) conducted a phase III trial involving 569 chemotherapy naïve advanced pancreatic patients randomly assigned to receive either standard gemcitabine plus placebo or gemcitabine plus erlotinib (100 or $150 \mathrm{mg} /$ day per os). As reported in Table IV, the median survival time and the PFS were statistically significant in the combination arm and led to the approval of erlotinib in combination with gemcitabine by the FDA as a first-line treatment for unresectable pancreatic cancer (70). Interestingly, the analysis of EGFR expression in the subgroup of patients treated with erlotinib showed no significant gain in terms of survival related to EGFR status while the presence of skin rash was associated with a significantly longer survival $(p=0.037)$. Some authors assume that this result is due in part to the techniques used to determine EGFR expression and in part to involvement of the tumoral microenvironment, including endothelial cells that could play an important role in the mechanism of action of erlotinib (71).

Erlotinib has also been evaluated in combination with capecitabine in gemcitabine refractory patients in a phase II study (72). The median PFS and OS were 3.4 and 6.5 months, respectively, with $10 \%$ partial response. This combination could be a valuable second-line treatment option in those patients who received a chemotherapy regimen containing gemcitabine as a first-line chemotherapy.

Cetuximab. Cetuximab is a chimeric IgG1 monoclonal antibody that specifically binds to the extracellular domain of EGFR preventing downstream signal transduction activations. Cetuximab significantly suppresses tumoral growth and reduces microvascular density by down-regulation of tumor cell-produced VEGF (vascular endothelial growth factor) and IL-8 with inhibition of tumor-induced angiogenesis (73).

Due to the interesting results of a phase I study (74), a phase II trial was designed to determine the efficacy and tolerability of cetuximab combined with gemcitabine in pathologically confirmed EGFR-expressing pancreatic cancer patients (75). Treatment was generally well-tolerated and the development of a skin rash, in particular grades 3-4, was associated with longer survival. These encouraging results were not confirmed in the subsequent studies $(76,77)$, as summarized in Table IV.

Gefitinib. This orally bioavailable active quinazoline tyrosine kinase inhibitor is a competitive inhibitor of ATP binding to the intracellular kinase domain of EGFR.

Fountzilas and colleagues published the results of a phase II study involving 53 inoperable or metastatic pancreatic cancer patients who received the combination of gefitinib plus gemcitabine. Median survival time and PFS were 7.3 and 4.1 months, respectively. The one-year survival rate was $27 \%$ and partial responses and stable disease were reported in 9 and $23 \%$ of patients, respectively (78).

Gefitinib was also evaluated, as a second-line treatment, in combination with docetaxel but the combination failed to be active as a salvage treatment after failure of gemcitabinebased chemotherapy (79).

Lapatinib. Lapatinib is a small molecule, orally administered, that reversibly inhibits both EGFR and HER2/neu tyrosine kinases.

Safran and colleagues published the results of a phase I trial evaluating the safety/tolerability and antitumor activity of lapatinib in combination with either gemcitabine or with GEMOX schedule in patients with naïve advanced pancreatic and biliary cancer. Lapatinib showed a median survival of 10 months among the 16 patients with metastatic pancreatic cancer (80).

A phase II study of lapatinib in combination with gemcitabine is currently ongoing in metastatic pancreatic patients.

Trastuzumab. Trastuzumab is a HER2 recombinant humanized IgG1 monoclonal antibody with a well-established therapeutic efficacy in breast carcinoma (81). As mentioned above, HER $2 /$ neu is overexpressed in pancreatic cancer in different ways.

An in vitro study on pancreatic cancer cell lines showed a correlation of cell growth inhibition with the expression levels of HER2/neu. These observations were confirmed in an orthotopic mouse model $(82,83)$.

A preliminary clinical trial evaluated the effectiveness and toxicity of trastuzumab plus gemcitabine in 34 metastatic pancreatic cancer patients with $2+/ 3+$ HER-2/neu expression by immunohistochemistry. Only 4 patients (16\%) had HER-2/ neu $3+$ overexpression. Confirmed partial responses were observed in 2 out of 32 patients $(6 \%)$ and the median survival was 7 months.

Further studies are needed to assess the real effectiveness and role of this molecule in the treatment of pancreatic cancer (84).

\section{Vascular endothelial growth factor (VEGF)}

VEGF is an important mediator of tumor angiogenesis. The progressive growth and metastasis of neoplasms depend in part on angiogenesis, the extent of which is determined by the balance between pro-angiogenic and anti-angiogenic molecules released by tumor cells and normal host cells.

VEGF is able to bind to specific receptors, VEGFR-1 (vascular endothelial growth factor receptor-1) and VEGFR-2 principally, which in turn activate specific downstream proliferation and survival pathways. VEGF is overexpressed in human pancreatic cancer and is associated with disease progression (85).

Bevacizumab. Bevacizumab, a humanized monoclonal immunoglobulin $\mathrm{G}$ antibody, inhibits all active isoforms of VEGF. A phase II study evaluated the combination of 
bevacizumab plus gemcitabine in 52 advanced pancreatic patients. Eleven patients $(21 \%)$ had partial responses and $24(46 \%)$ had stable disease. The six-month and one-year survival rates were 77 and $29 \%$ while the median OS and PFS were 8.8 and 5.4 months, respectively. The main grade 3 and 4 toxicities included hypertension, thrombosis, visceral perforation and bleeding (86).

These interesting results led to a phase III study that failed to confirm the previous findings (Kindler HL, et al, ASCO Gastrointestinal Cancers Symposium, abs. 108, 2007). Therefore, a double-blind, placebo controlled, multicenter phase III randomized trial was conducted to evaluate the efficacy and safety of the bevacizumab, erlotinib and gemcitabine combination in metastatic pancreatic cancer patients. Median OS was not statistically significant between the two treatment arms but PFS was significantly improved in the bevacizumab arm Table IV (87). Bevacizumab was also evaluated in a small multicentric phase II study in combination with gemcitabine and capecitabine in 50 advanced pancreatic patients. One patient achieved a complete response $(2 \%), 10$ partial response $(20 \%)$ and 30 stable disease $(60 \%)$. Median PFS and OS were 5.8 and 9.8 months, respectively (Iyer RV, et al, Gastrointestinal Cancers Symposium, abs. 198, 2008).

Sorafenib. Sorafenib is an oral multikinase inhibitor able to inhibit the tumor growth targeting MAPK pathway by Raf-kinase, VEGF-R2, -R3 and platelet-derived growth factor receptor (PDGFR)- $\beta$. This small oral molecule is under evaluation in some clinical trials alone or in combination with chemotherapeutic agents in many types of cancer.

The combination of sorafenib plus gemcitabine was tested in pancreatic cancer patients in two small clinical trials. A phase I study was conducted on 23 patients and $56 \%$ of them showed evidence of disease stabilization, whereas a more recent phase II trial on 17 patients showed no efficacy in advanced pancreatic cancer $(88,89)$.

\section{Other molecules}

Marimastat. Matrix metalloproteinases (MMPs) are a family of zinc-dependent proteolytic enzymes responsible for the degradation of connective tissue proteins. Aberrant MMP expression contributes to the invasive growth and spread of a variety of solid malignancies (90).

The interesting results obtained in animal models were not confirmed in clinical practice. In particular, marimastat, an oral MMP, was evaluated in a randomized phase III trial in 414 locally advanced pancreatic patients yielding one-year survival rates similar to those in patients who had received gemcitabine (91). However, a subsequent phase III study failed to show any significant improvement in terms of clinical benefit of marimastat over gemcitabine alone (92).

Tipifarnib. Tipifarnib is an oral non-peptidomimetic farnesyl transferase inhibitor which demonstrated anti-proliferative effects in a wide array of tumor cell lines including those of pancreatic origin.

Farnesylation is an important post-translational event required for Ras activation. This proto-oncogene, in particular $\mathrm{K}$-Ras, is frequently mutated in pancreatic cancer and is responsible for the increased tumor proliferation, invasiveness, resistance to apoptosis and metastasis (93).

The clinical impact of Tipifarnib in pancreatic cancer has been a failure and did not improve OS either as a single agent or in combination with gemcitabine over gemcitabine alone $(94,95)$.

\section{Second-line treatments}

There is still no indication for standardized second-line chemotherapy in advanced pancreatic patients, but in the last few years many trials have studied different regimes in gemcitabine pre-treated patients. The first second-line study was done by Oettle and colleagues. They proved the efficacy of the oxaliplatin and 5-FU regimen with interesting results such as an increased survival with a median value of 4.8 months compared to the 2.8 months in the BSC arm ( $\mathrm{p}=0.007)$ (96).

Platinum compounds and 5-FU are also being widely studied in these patients (97). A phase II trial showed the efficacy of an oxaliplatin, leucovorin and 5-FU regimen, with a median OS of 25 weeks (98). In the wake of this study, Gebbia and colleagues proposed the FOLFOX4 regimen as a second-line therapy, obtaining a median TTP and OS of 4.0 and 6.7 months, respectively (99).

The capecitabine and oxaliplatin combination has also been tested in gemcitabine pre-treated pancreatic patients. A recent phase II showed the good activity of this combination, especially in patients with good PS; the median OS was 23 weeks and a one-year survival rates was $21 \%$ (100).

Among platinum-combination trials, the multidrug combination regimen PEFG was also studied as a second-line treatment option. Reni and colleagues showed promising results with an OS of 8.3 months and PFS of 5 months (101).

Disappointing data came from taxane combination trials: the docetaxel-gefitinib association in a phase II trial demonstrated no activity as a salvage treatment (79).

The role of topoisomerase inhibitors in gemcitabine pretreated patients has also been discussed. CPT-11 as a single agent showed a small efficacy in terms of PFS (2.0 months) and OS (6.6 months) (102), but the combination with oxaliplatin showed a good synergistic activity in the trial of Cantore and colleagues, with a median OS value of 5.9 months and a median PFS of 4.1 months (103).

Other trials analyzed the use of pemetrexed as a secondline agent. A multicenter phase II study showed a TTP of 7 weeks and a median OS of 20 weeks, while a pemetrexedirinotecan combination trial demonstrated moderate activity in advanced pancreatic patients after failure of gemcitabine (104).

\section{Conclusions}

All the studies examined in this review demonstrate and confirm that advanced pancreatic cancer is among the most complex cancers to treat. Since the approval of gemcitabine as a standard treatment for advanced pancreatic patients, no drug or combination of drugs has significantly improved the prognosis. However, gemcitabine-based regimens or more toxic schedules may be reserved for patients with good PS. 
A better understanding of pancreatic cancer biology, earlier diagnosis and a better selection of patients on the basis of specific bio-pathological characteristics will help oncologists to improve the clinical management and outcome of these patients.

\section{References}

1. Jemal A, Siegel R, Ward E, Murray T, Xu J and Thun MJ: Cancer Statistics 2007. CA Cancer J Clin 57: 43-66, 2007.

2. Loos M, Kleeff J, Friess H and Büchler MW: Surgical treatment of pancreatic cancer. Ann N Y Acad Sci 1138: 169-180, 2008

3. Sultana A, Smith CT, Cunningham D, Starling N, Neoptolemos JP and Ghaneh PJ: Meta-analyses of chemotherapy for locally advanced and metastatic pancreatic cancer. J Clin Oncol 25: 2607-2615, 2007.

4. Yip D, Karapetis C, Strickland A, Steer CB and Goldstein D: Chemotherapy and radiotherapy for inoperable advanced pancreatic cancer (Review). Cochrane Database Syst Rev 19: 3, 2006.

5. Cullinan S, Moertel CG, Wieand HS, et al: A phase III trial on the therapy of advanced pancreatic carcinoma. Evaluations of the Mallison regimen and combined 5-fluorouracil, doxorubicin, and cisplatin. Cancer 15: 2207-2212, 1990.

6. Kelsen D, Hudis C, Niedzwiecki D, et al: A phase III comparison trial of streptozotocin, mitomycin, and 5-fluorouracil with cisplatin, cytosine arabinoside, and caffeine in patients with advanced pancreatic carcinoma. Cancer 68: 965$969,1991$.

7. Ducreux M, Rouguer P, Pignon JP, et al: A randomized trial comparing 5-FU with 5-FU plus cisplatin in advanced pancreatic carcinoma. Ann Oncol 13: 1185-1191, 2002.

8. Maisey N, Chau I, Cunningham D, et al: Multicenter randomized phase III trial comparing protracted venous infusion (PVI) fluorouracil (5-FU) with PVI 5-FU plus mitomycin in inoperable pancreatic cancer. J Clin Oncol 20: 3130-3136, 2002.

9. Ducreux M, Mitry E, Ould-Kaci M, et al: Randomized phase II study evaluating oxaliplatin alone, oxaliplatin combined with infusional 5-FU, and infusional 5-FU alone in advanced pancreatic carcinoma patients. Ann Oncol 15: 467-473, 2004.

10. Casper ES, Green MR, Kelsen DP, et al: Phase II trial of gemcitabine (2,2'-difluorodeoxycytidine) in patients with adenocarcinoma of the pancreas. Invest New Drugs 12: 29-34, 1994.

11. Carmichael J, Fink U, Russel RC, Spittle MF, Harris AL, Spiessi G and Blatter J: Phase II study of gemcitabine in patients with advanced pancreatic cancer. Br J Cancer 73: 101-105, 1996.

12. Rothenberg ML, Moore MJ, Cripps MC, et al: A phase II trial of gemcitabine in patients with 5-FU-refractory pancreatic cancer. Ann Oncol 7: 347-353, 1996.

13. Burris HA, Moore MJ, Andersen J, et al: Improvement in survival and clinical benefit with gemcitabine as first line therapy for patients with advanced pancreatic cancer: a randomised trial. J Clin Oncol 15: 2403-2413, 1997.

14. Gelibter A, Malaguti P, Di Cosimo S, et al: Fixed dose-rate gemcitabine infusion as first-line treatment for advanced-stage carcinoma of the pancreas and biliary tree. Cancer (Suppl) 104: 1237-1245, 2005.

15. Tempero M, Plunkett W, Ruiz Van Haperen V, Hainsworth J, Hochster H, Lenzi R and Abbruzzese J: Randomized phase II comparison of dose-intense gemcitabine: thirty-minute infusion and fixed dose rate infusion in patients with pancreatic adenocarcinoma. J Clin Oncol 21: 3402-3408, 2003.

16. Poplin E, Levy D, Berlin J, et al: Phase III trial of gemcitabine (30 min infusion) versus gemcitabine fixed-dose rate infusion (FDR) versus gemcitabine + oxaliplatin (GEMOX) in patients with advanced pancreatic cancer (E6201). J Clin Oncol 24: S18, 2006

17. Banu E, Banu A, Fodor A, et al: Meta-analysis of randomized trials comparing gemcitabine-based doublets versus gemcitabine alone in patients with advanced and metastatic pancreatic cancer. Drugs Asing 24: 865-879, 2007.

18. Heinemann V, Böck S, Hinke A, Labianca R and Louvet C: Meta-analysis of randomized trials: evaluation of benefit from gemcitabine-based combination chemotherapy applied in advanced pancreatic cancer. BMC Cancer 8: 82, 2008.
19. Berlin JD, Adak S, Vaughn DJ, Flinker D, Blaszkowsky L, Harris JE and Benson AB III: A phase II study of gemcitabine and 5-fluorouracil in metastatic pancreatic cancer: an Eastern Cooperative Oncology Group study (E3296). Oncology 58: 215-218, 2000

20. Cascinu S, Silva RR, Barni S, et al: A combination of gemcitabine and 5-fluorouracil in advanced pancreatic cancer, a report from the Italian group for Study of Digestive Tract Cancer (GISCAD). Br J Cancer 80: 1595-1598, 1990.

21. Oettle H, Pelzer U, Hochmuth K, et al: Phase I trial of gemcitabine (Gemzar), $24 \mathrm{~h}$ infusion 5-fluorouracil and folinic acid in patients with inoperable pancreatic cancer. Anticancer Drugs 10: 699-704, 1999.

22. Oettle H, Arning M, Pelzer U, et al: A phase II trial of gemcitabine in combination with 5-fluorouracil (24-hour) and folinic acid in patients with chemonaive advanced pancreatic cancer. Ann Oncol 11: 1267-1272, 2000.

23. Berlin JD, Catalano P, Thomas JP, Kugler JW, Haller DG and Benson III AB: Phase III study of gemcitabine in combination with fluorouracil versus gemcitabine alone in patients with advanced pancreatic carcinoma: Eastern Cooperative Oncology Group Trial E2297. J Clin Oncol 20: 3270-3275, 2002.

24. Di Costanzo F, Carlini P, Doni L, et al: Gemcitabine with or without continuous infusion 5-FU in advanced pancreatic cancer: a randomised phase II trial of the Italian oncology group for clinical research (GOIRC). Br J Cancer 93: 185-189, 2005.

25. Schilsky RL, Bertucci D, Vogelzang NJ, Kindler HL and Ratain MJ: Dose-escalating study of capecitabine plus gemcitabine combination therapy in patients with advanced cancer. J Clin Oncol 20: 582-587, 2002.

26. Hess V, Salzberg M, Borner M, Morant R, Roth AD, Ludwig C and Herrmann R: Combining capecitabine and gemcitabine in patients with advanced pancreatic carcinoma: a phase I/II trial. J Clin Oncol 21: 66-68, 2003.

27. Cartwright T, Cohn A, Varkey J, Chen Y, Szatrowski T, Cox J and Schulz J: Phase II study of oral capecitabine in patients with advanced or metastatic pancreatic cancer. J Clin Oncol 20: 160-164, 2001

28. Park BB, Park JO, Lee HR, et al: A phase II trial of gemcitabine plus capecitabine for patients with advanced pancreatic adenocarcinoma. Cancer Chemother Pharmacol 60: 489-494, 2007.

29. Scheithauer W, Schull B, Ulrich-Pur H, et al: Biweekly highdose gemcitabine alone or in combination with capecitabine in patients with metastatic pancreatic adenocarcinoma: a randomized phase II trial. Ann Oncol 14: 97-104, 2003.

30. Cunningham D, Chan I, Stocken D, et al: Phase III randomized comparison of gemcitabine (GEM) versus gemcitabine plus capecitabine (GEM-CAP) in patients with advanced pancreatic cancer. Eur J Cancer (Suppl. 3): PS11, 2005.

31. Herrmann R, Bodoky G, Ruhstaller T, et al: Gemcitabine plus capecitabine compared with gemcitabine alone in advanced pancreatic cancer: a randomized, multicenter, phase III trial of the swiss group for clinical cancer research and the central European cooperative oncology group. J Clin Oncol 25: 2212-2217, 2007.

32. Bernhard J, Dietrich D, Scheithauer W, et al: Clinical benefit and quality of life in patients with advanced pancreatic cancer receiving gemcitabine plus capecitabine versus gemcitabine alone: a randomized multicenter phase III clinical trial - SAKK 44/00-CECOG/PAN.1.3.001. J Clin Oncol 26: 3695-3701, 2008.

33. Ueno H, Okada S, Okusaka T, Ikeda M and Kuriyama H: Phase II study of uracil-tegafur in patients with metastatic pancreatic cancer. Oncology 62: 223-227, 2002.

34. Feliu J, Mel R, Borrega P, et al: Phase II study of a fixed doserate infusion of gemcitabine associated with uracil/tegafur in advanced carcinoma of the pancreas. Ann Oncol 13: 1756-1762, 2002.

35. Lee J, Park JO, Kim WS, et al: Phase II study of gemcitabine combined with uracil-tegafur in metastatic pancreatic cancer. Oncology 66: 32-37, 2004.

36. Ueno H, Okusaka T, Ikeda M, et al: A phase I study of combination chemotherapy with gemcitabine and oral S-1 for advanced pancreatic cancer. Oncology 69: 421-427, 2005.

37. Heinemann V, Wilke H, Mergenthaler HG, et al: Gemcitabine and cisplatin in the treatment of advanced or metastatic pancreatic cancer. Ann Oncol 11: 1399-1403, 2000.

38. Cascinu S, Labianca R, Catalano V, et al: Weekly gemcitabine and cisplatin chemotherapy: a well-tolerated but ineffective chemotherapeutic regimen in advanced pancreatic cancer patients. A report from the Italian Group for the Study of Digestive Tract Cancer (GISCAD). Ann Oncol 14: 205-208, 2003. 
39. Philip PA, Zalupski MM, Vaitkevicius VK, et al: Phase II study of gemcitabine and cisplatin in the treatment of patients with advanced pancreatic carcinoma. Cancer 92: 569-577, 2001

40. Ko AH, Dito E, Schillinger B, Bergsland EK, Dito E, Schillinger B and Tempero MA: Phase II study of fixed dose rate gemcitabine with cisplatin for metastatic adenocarcinoma of the pancreas. J Clin Oncol 24: 379-385, 2006.

41. Airoldi M, Cattel L, Passera R, Pedani F, Milla P and Zanon C: Gemcitabine and oxaliplatin in patients with pancreatic adenocarcinoma. Pancreas 32: 44-50, 2006

42. Ueno H, Okusaka T, Ikeda M, Morizane C, Ogura T, Hagihara A and Tanaka T: Phase II study of combination chemotherapy with gemcitabine and cisplatin for patients with metastatic pancreatic cancer. Jpn J Clin Oncol 37: 515-520, 2007.

43. Alberts SR, Townley PM, Goldberg RM, et al: Gemcitabine and oxaliplatin for metastatic pancreatic adenocarcinoma: a north central cancer treatment group phase II study. Ann Oncol 14: 580-585, 2003

44. Clayton AJ, Mansoor AW, Jones ET, Hawkins RE, Saunders MP, Swindell R and Valle JW: A phase II study of weekly cisplatin and gemcitabine in patients with advanced pancreatic cancer: is this a strategy still worth pursuing? Pancreas $32: 51-57$, 2006.

45. Louvet C, André T, Lledo G, et al: Gemcitabine combined with oxaliplatin in advanced pancreatic adenocarcinoma: final results of a GERCOR multicenter Phase II study. J Clin Oncol 20: 1512-1518, 2002.

46. Louvet C, Labianca R, Hammel P, et al: Gemcitabine in combination with oxaliplatin compared with gemcitabine alone in locally advanced or metastatic pancreatic cancer: results of a GERCOR and GISCAD phase III trial. J Clin Oncol 23: 3509-3516, 2005.

47. Colucci G, Giuliani F, Gebbia V, et al: Gemcitabine alone or with cisplatin for the treatment of patients with locally advanced and/or metastatic pancreatic carcinoma. Cancer 94: 902-910, 2002

48. Heinemann V, Quietzsch D, Gieseler F, et al: Randomized Phase III trial of gemcitabine plus cisplatin compared with gemcitabine alone in advanced pancreatic cancer. J Clin Oncol 24: 3946-3952, 2006

49. Miller KD, Picus J, Blanke C, et al: Phase II study of the multitargeted antifolate LY231514 (ALIMTA, MTA, pemetrexed disodium) in patients with advanced pancreatic cancer. Ann Oncol 11: 101-103, 2000

50. Oettle H, Richards D, Ramanathan RK, et al: A phase III trial of pemetrexed plus gemcitabine versus gemcitabine in patients with unresecable or metastatic pancreatic cancer. Ann Oncol 16: $1639-1645,2005$

51. Sakata Y, Shimada Y, Yoshino M, et al: A late phase II study of CPT-11, irinotecan hydrochloride, in patients with advanced pancreatic cancer. CPT-11 Study Group on Gastrointestinal Cancer. Gan To Kagak Ryoho 21: 1039-1046, 1994.

52. Wagener DJ, Verdonk HE, Dirix LY, et al: Phase II trial of CPT-11 in patients with advanced pancreatic cancer, an EORTC early clinical trials group study. Ann Oncol 6: 129-132, 1995.

53. Rocha Lima CM, Savarese D, Bruckner H, et al: Irinotecan plus gemcitabine induces both radiographic and CA 19-9 tumor marker responses in patients with previously untreated advanced pancreatic cancer. J Clin Oncol 20: 1182-1191, 2002.

54. Rocha Lima CM, Green MR, Rotche R, et al: Irinotecan plus gemcitabine results in no survival advantage compared with gemcitabine monotherapy in patients with locally advanced or metastatic pancreatic cancer despite increased tumor response rate. J Clin Oncol 22: 3776-3783, 2004.

55. Abou-Alfa GK, Letourneau R, Harker G, et al: Randomized phase III study of exatecan and gemcitabine compared with gemcitabine alone in untreated advanced pancreatic cancer. J Clin Oncol 24: 4441-4447, 2006.

56. Goel A, Grossbard ML, Malamud S, et al: Pooled efficacy analysis from a phase I-II study of biweekly irinotecan in combination with gemcitabine, 5-fluorouracil, leucovorin and cisplatin in patients with metastatic pancreatic cancer. Anticancer Drugs 18: 263-271, 2007.

57. Sherman WH and Fine RL: Combination gemcitabine and docetaxel therapy in advanced adenocarcinoma of the pancreas. Oncology 60: 316-321, 2001

58. Schneider BP, Ganjoo KN, Seitz DE, et al: Phase II study of gemcitabine plus docetaxel in advanced pancreatic cancer: a Hoosier Oncology Group study. Oncology 65: 218-223, 2003
59. Cascinu S, Gasparini G, Catalano V, et al: A phase I-II study of gemcitabine and docetaxel in advanced pancreatic cancer: a report from the Italian Group for the Study of Digestive Tract Cancer (GISCAD). Ann Oncol 10: 1377-1379, 1999.

60. Ryan DP, Kulke MH, Fuchs CS, et al: A phase II study of gemcitabione and docetaxel in patients with metastatic pancreatic carcinoma. Cancer 94: 97-103, 2002.

61. Shepard RC, Levy DE, Berlin JD, et al: Phase II study of gemcitabine in combination with docetaxel in patients with advanced pancreatic carcinoma (E1298). A trial of the Eastern Cooperative Oncology Group. Oncology 66: 303-309, 2004.

62. Reni M, Cordio S, Milandri C, et al: Gemcitabine versus cisplatin, epirubicin, fluoruracil, and gemcitabine in advanced pancreatic cancer: a randomised controlled multicentre phase III trial. Lancet Oncol 6: 369-376, 2005.

63. Ghosn M, Farhat F, Kattan J, Younes F, Moukadem W, Nasr F and Chahine G: FOLFOX-6 combination as the first-line treatment of locally advanced and/or metastatic pancreatic cancer. J Clin Oncol 30: 15-20, 2007

64. Taïeb J, Lecomte T, Aparicio T, et al: FOLFIRI 3 , a new regimen combining 5-fluorouracil, folinic acid and irinotecan, for advanced pancreatic cancer: results of an Association des GastroEnterologues Oncologues (Gastroenterologist Oncologist Association) multicenter phase II study. Ann Oncol 18: 498-503, 2007.

65. Yamanaka Y, Friess H, Kobrin MS, Buchler M, Beger HG and Korc M: Coexpression of epidermal growth factor receptor and ligands in human pancreatic cancer is associated with enhanced tumor aggressiveness. Anticancer Res 13: 565-569, 1993.

66. Potti A, Ganti AK, Tendulkar K, Chitajallu S, Sholes K, Koch M and Kargas S: HER-2/neu and CD117 (C-kit) overexpression in hepatocellular and pancreatic carcinoma. Anticancer Res 23: 2671-2674, 2003

67. Dergham ST, Dugan MC, Arlauskas P, et al: Relationship of family cancer history to the expression of p53, p21WAF-1, HER-2/neu, and K-ras mutation in pancreatic adenocarcinoma. Int J Pancreatol 21: 225-234, 1997.

68. Hidalgo M, Siu LL, Nemunaitis J, et al: Phase I and pharmacologic study of OSI-774, an epidermal growth factor receptor tyrosine kinase inhibitor, in patients with advanced solid malignancies. J Clin Oncol 19: 3267-3279, 2001

69. Dragovich T, Huberman M, Von Hoff DD, et al: Erlotinib plus gemcitabine in patients with unresectable pancreatic cancer and other solid tumors: phase IB trial. Cancer Chemother Pharmacol 60: 295-303, 2007.

70. Moore MJ, Goldstein D, Hamm J, et al: Erlotinib plus gemcitabine compared with gemcitabine alone in patients with advanced pancreatic cancer: a phase III trial of the National Cancer Institute of Canada Clinical Trials Group. J Clin Oncol 25: 1960-1966, 2007

71. Normanno N and De Luca A: Erlotinib in Pancreatic Cancer: Are Tumor Cells the (only) Target? J Clin Oncol 25: 5836-5837, 2007.

72. Kulke MH, Blaszkowsky LS, Ryan DP, et al: Capecitabine plus erlotinib in gemcitabine-refractory advanced pancreatic cancer. J Clin Oncol 25: 4787-4792, 2007

73. Bruns CJ, Harbison MT, Davis DW, et al: Epidermal growth factor receptor blockade with $\mathrm{C} 225$ plus gemcitabine results in regression of human pancreatic carcinoma growing orthotopically in nude mice by antiangiogenic mechanisms. Clin Cancer Res 6: 1936-1948, 2000.

74. Baselga J, Pfister D, Cooper MR, et al: Phase I studies of antiepidermal growth factor receptor chimeric antibody C225 alone and in combination with cisplatin. J Clin Oncol 18: 904-914, 2000.

75. Xiong HQ, Rosenberg A, LoBuglio A, et al: Cetuximab, a monoclonal antibody targeting the epidermal growth factor receptor, in combination with gemcitabine for advanced pancreatic cancer: a multicenter phase II Trial. J Clin Oncol 22: 2610-2616, 2004.

76. Philip PA, Benedetti J, Fenoglio-Preiser C, et al: Phase III study of gemcitabine $(\mathrm{G})$ plus cetuximab $(\mathrm{C})$ versus gemcitabine in patients (pts) with locally advanced or metastatic pancreatic adenocarcinoma (PC): SWOG S0205 study. J Clin Oncol 25: S18, 2007.

77. Cascinu S, Berardi R, Labianca R, et al: Cetuximab plus gemcitabine and cisplatin compared with gemcitabine and cisplatin alone in patients with advanced pancreatic cancer: a randomised, multicentre, phase II trial. Lancet Oncol 9: $39-44,2008$. 
78. Fountzilas G, Bobos M, Kalogera-Fountzila A, et al: Gemcitabine combined with gefitinib in patients with inoperable or metastatic pancreatic cancer: a phase II Study of the Hellenic Cooperative Oncology Group with biomarker evaluation. Cancer Invest 26: 784-793, 2008.

79. Ignatiadis M, Polyzos A, Stathopoulos GP, et al : A multicenter phase II study of docetaxel in combination with gefitinib in gemcitabine-pretreated patients with advanced/metastatic pancreatic cancer. Oncology 71: 159-163, 2006.

80. Safran H, Miner T, Resnick M, et al: Lapatinib/gemcitabine and lapatinib/gemcitabine/oxaliplatin: a phase I study for advanced pancreaticobiliary cancer. Am J Clin Oncol 31: 140-144, 2008.

81. Slamon DJ, Leyland-Jones B, Shak S, et al: Use of chemotherapy plus a monoclonal antibody against HER2 for metastatic breast cancer that overexpresses HER2. N Engl J Med 344: 783-792, 2001

82. Buchler P, Reber HA, Buchler MC, et al: Therapy for pancreatic cancer with a recombinant humanized anti-HER2 antibody (herceptin). J Gastrointest Surg 5: 139-146, 2001.

83. Kimura K, Sawada T, Komatsu M, et al: Antitumor effect of trastuzumab for pancreatic cancer with high HER-2 expression and enhancement of effect by combined therapy with gemcitabine. Clin Cancer Res 12: 4925-4932, 2006.

84. Safran H, Iannitti D, Ramanathan R, et al: Herceptin and gemcitabine for metastatic pancreatic cancers that overexpress HER-2/neu. Cancer Invest 22: 706-712, 2004.

85. Itakura J, Ishiwata $\mathrm{T}$, Friess H, Fujii H, Matsumoto Y, Büchler MW and Korc M: Enhanced expression of vascular endothelial growth factor in human pancreatic cancer correlates with local disease progression. Clin Cancer Res 3: 1309-1316, 1997.

86 Kindler HL, Friberg G, Singh DA, et al: Phase II trial of bevacizumab plus gemcitabine in patients with advanced pancreatic cancer. J Clin Oncol 23: 8033-8040, 2005.

87. Van Cutsem E, Vervenne WL, Bennouna J, et al: Phase III tria of bevacizumab in combination with gemcitabine and erlotinib in patients with metastatic pancreatic cancer. J Clin Oncol 27: 2231-2237, 2009.

88. Siu LL, Awada A, Takimoto $\mathrm{CH}$, et al: Phase I trial of sorafenib and gemcitabine in advanced solid tumors with an expanded cohort in advanced pancreatic cancer. Clin Cancer Res 12 144-151, 2006.

89. Wallace JA, Locker G, Nattam S, et al: Sorafenib (S) plus gemcitabine $(\mathrm{G})$ for advanced pancreatic cancer $(\mathrm{PC})$ : a phase II trial of the University of Chicago Phase II Consortium. J Clin Oncol 25: 4608, 2007

90. Chambers AF, Matrisian LM: Changing views of the role of matrix metalloproteinases in metastasis. J Natl Cancer Inst 89: 1260-1270, 1997.

91. Bramhall SR, Schulz J, Nemunaitis J, Brown PD, Baillet M and Buckels JA: A double-blind placebo-controlled, randomised study comparing gemcitabine and marimastat with gemcitabine and placebo as first line therapy in patients with advanced pancreatic cancer. Br J Cancer 87: 161-167, 2002.
92. Bramhall SR, Rosemurgy A, Brown PD, Buckels JA, Marimastat Pancreatic Cancer Study: Marimastat pancreatic cancer study group: marimastat as first-line therapy for patients with unresectable pancreatic cancer: a randomized trial. J Clin Oncol 19: 3447-3455, 2001

93. Borja-Cacho D, Jensen EH, Saluja AK, Buchsbaum DJ and Vickers SM: Molecular targeted therapies for pancreatic cancer. Am J Surg 196: 430-441, 2008.

94. Danovi SA, Wong HH and Lemoine NR: Targeted therapies for pancreatic cancer. Br Med Bull 87: 97-130, 2008.

95. Van Cutsem E, van de Velde H, Karasek P, et al: Phase III trial of gemcitabine plus tipifarnib compared with gemcitabine plus placebo in advanced pancreatic cancer. J Clin Oncol 22: 1430-1438, 2004.

96. Oettle H, Pelzer U, Stieler J, et al: Oxaliplatin/folinic acid/5fluorouracil $(24 \mathrm{~h})$ plus best supportive care versus best supportive care alone (BSC) in second-line therapy of gemcitabine-refractory advanced pancreatic cancer $(\mathrm{CONKO}$ 003). J Clin Oncol 23: S315, 2005.

97. Reni M, Berardi R, Mambrini A, et al: A multi-centre retrospective review of second-line therapy in advanced pancreatic adenocarcinoma. Cancer Chemother Pharmacol 62: 673-678, 2008.

98. Tsavaris N, Kosmas C, Skopelitis H, et al: Second-line treatment with oxaliplatin, leucovorin and 5-fluorouracil in gemcitabine-pretreated advanced pancreatic cancer: A phase II study. Invest New Drugs 23: 369-375, 2005.

99. Gebbia V, Maiello E, Giuliani F, et al: Second-line chemotherapy in advanced pancreatic carcinoma: a multicenter survery of the Gruppo Oncologico Italia Meridionale on the activity and safety of the FOLFOX4 regimen in clinical practice. Ann Oncol 18: 124-127, 2007.

100. Xiong HQ, Varadhachary GR, Blais JC, Hess KR, Abbruzzese JL and Wolff RA: Phase II trial of oxaliplatin plus capecitabine (XELOX) as second-line therapy for patients with advanced pancreatic cancer. Cancer 113: 2046-2052, 2008.

101. Reni M, Cereda S, Mazza E, et al: PEFG (cisplatin, epirubicin, 5-fluorouracil, gemcitabine) regimen as second-line therapy in patients with progressive or recurrent pancreatic cancer after gemcitabine-containing chemotherapy. Am J Clin Oncol 31: 145-150, 2008 .

102. Yi SY, Park YS, Kim HS, et al: Irinotecan monotherapy as second-line treatment in advanced pancreatic cancer. Cancer Chemother Pharmacol 63: 1141-1145, 2009.

103. Cantore M, Rabbi C, Fiorentini G, et al: Combined irinotecan and oxaliplatin in patients with advanced pre-treated pancreatic cancer. Oncology 67: 93-97, 2004.

104. Boeck S, Weigang-Kohler K, Fuchs M, et al: Second line chemotherapy with pemetrexed after gemcitabine failure in patients with advanced pancreatic cancer: a multicenter phase II trial. Ann Oncol 18: 745-751, 2007. 